\title{
LA REFLEXIÓN SOBRE LAS RELIGIONES MISTÉRICAS EN LA FILOSOFÍA DE NIETZSCHE
}

The Thoughts about Mistery Cults in Nietzsche's Philosophy

\author{
Carlotta Santini
}

Università del Salento, Lecce

RESUMEN: Los misterios griegos son para Nietzsche una de las expresiones más originales y significativas de la espiritualidad antigua. En el curso de su vida y de sus estudios se dirigirá a menudo a los misterios con la curiosidad del filólogo y del etnólogo, pero también con el ojo especulativo del filósofo. Al análisis histórico en extensión hace de contrapeso un intento continuo de trasformar la semántica del fenómeno de los misterios, a lo largo de un recorrido a menudo difícil y errático que atraviesa toda la obra del autor.

Palabras clave: misterios - dionisíaco - misticismo - cristianismo

AвSTRACT: The Greek mysteries are for Nietzsche one of the most original and significant expressions of Ancient spirituality. During his life and his studies Nietzsche will deserve much attention to the Mysteries with the curiosity of a philologist and an ethnologist, but also with the speculative eye of the philosopher. To the historical analyse corresponds a continual attempt to transform the semantics of the phenomenon of mysteries, along a way that is often hard and contrasting, but that goes through all the work of the author.

Keywords: Mysteries - Dionysian - Mysticism - Christianity

Entre las cuestiones más interesantes que se pueden abordar en torno a la compleja y riquísima relación de Nietzsche con el mundo antiguo, una de las más difíciles y por tanto más dignas de estudio es la de los misterios. Ante todo, el objeto mismo de la cuestión es huidizo, este enigmático fenómeno religioso del que se sabe poco porque estaba envuelto en un estricto secreto y sobre cuya naturaleza los estudiosos de la historia de las religiones siguen interrogándose hoy día. Los estudiosos nietzscheanos no han demostrado un interés particular por la presencia de este tema en la obra del filósofo, excepto unos pocos y significativos estudios ${ }^{1}$. El problema es la costumbre de reconducir la cuestión de los misterios a la cuestión más general del dionisismo, planteamiento que parece estar apoyado por Nietzsche mismo en algunos lugares del texto. En realidad, la reflexión sobre el significado del fenómeno de los misterios en la Antigüedad

1. Estudios imprescindibles sobre el tema son H. Cancik y H. Cancik-Lindemaier, Nietzsches «Mysterienlehre», en M. Babler y H. Châtellier (ed.), Mystique, mysticisme et modernité en Allemagne autour de 1900. Mystik, Mystizismus und Moderne in Deutschland um 1900, Presses Universitaires de Strasbourg, 1998, pp. 59-73; B. Biebuyck, D. Praet y I. Vanden Poel, Cults and migrations: Nietzsche's Meditations on Orphism, Pythagoreanism, and the Greek Mysteries, en P. Bishop (ed.), Nietzsche and antiquity: his reaction and response to the classical tradition, Camden House, 2004, pp. 151-169. 
atraviesa toda la obra de Nietzsche, prácticamente sin interrupciones. Pero no podemos decir que esta reflexión sea unívoca, ni siquiera perfectamente coherente y expresión de un discurso unitario. Por consiguiente, mi contribución, lejos de la pretensión de resultar exhaustiva, quiere invitar a profundizar en una serie de temáticas complejas y ricas de implicaciones, fundamentales para una mejor comprensión del pensamiento nietzscheano. Es interesante ver de qué modo Nietzsche aborda la complejidad del fenómeno de los misterios, cómo responde con una profunda reflexión filosófica, y de qué modo, al hacer esto, se remite a corrientes culturales de su época.

Justo en la época de Nietzsche, el interés de los estudiosos comenzaba a dirigirse hacia este tipo especial de prácticas religiosas. En el paso de pocas generaciones se publicaban los primeros textos especializados sobre el tema, que señalaban el inicio de los estudios sobre las religiones mistéricas. Por citar algunos de los más significativos de los que Nietzsche conocía y había estudiado: la Symbolik de Friedrich Creuzer ${ }^{2}$, que fue un escándalo y dio lugar a la respuesta polémica inmediata de Heinrich Voss ${ }^{3}$; el muy criticado (al menos por Nietzsche) Aglaophamus de Christian August Lobeck ${ }^{4}$, la Gräbersymbolik de Bachofen ${ }^{5}$. El texto más importante de esta serie de estudios, que aún hoy en día es una referencia en la disciplina, fue el bellísimo libro de Erwin Rohde Psyche ${ }^{6}$, que, sin embargo, Nietzsche no pudo conocer. Además de estas obras más específicas, muchos textos conocidos por Nietzsche, y que consultaba con frecuencia, contienen importantes secciones dedicadas al fenómeno religioso de los misterios. Recordemos aquí dos obras de Jacob Burckhardt, la Kulturgeschichte ${ }^{7}$ y Die Zeit Konstantins des Großen ${ }^{8}$, esta última en cuanto al fenómeno específico de los misterios en la Antigüedad tardía; la Griechische Mythologie de Ludwig Preller', con su fundamental sección sobre las divinidades subterráneas; la Griechische Götterlehre de Friedrich Welcker ${ }^{10}$; la Culturgeschichte de Hermann ${ }^{11}$ y la im-

2. F. Creuzer, Symbolik und Mythologie der alten Völker besonders der Griechen, Leipzig/ Darmstadt: Leske, 1810.

3. H. Voss, Antisymbolik, Stuttgart: J. B. Metzler, 1826.

4. Ch. A. Lobeck, Aglaophamus, sive de theologiae mysticae Graecorum causis libri tres, Königsberg: Regimontii Prussorum, 1829. Es oportuno recordar el juicio negativo que expresa Nietzsche sobre esta obra en Crepúsculo de los ídolos: «Sobre todo el famoso Lobeck, que se introdujo a rastras en este mundo de estados misteriosos con la venerable seguridad de un gusano desecado entre libros, y se persuadió de que era científico siendo frívolo e infantil hasta la náusea» (CI, «Lo que debo a los antiguos» $\mathbb{\$} 4$, Madrid: Alianza, ${ }_{6} 1982$, p. 133).

5. J. J. Bachofen, Versuch über die Gräbersymbolik der Alten, Basel, 1859. Con respecto a la obra principal de Bachofen, Das Mutterrecht, no se ha podido comprobar si Nietzsche la llegó a leer.

6. E. Rohde, Psyche. Seelencultund Unsterblichkeitsglaubeder Griechen, Freiburg i. Br., 1890-1894.

7. Jacob Burckhardt había impartido en Basilea varios ciclos de lecciones, que después serán recogidos en la obra que conocemos con el título de Griechische Kulturgeschichte. Nietzsche la conocía bien incluso en las modificaciones que Burckhardt iba introduciendo en ella, como atestigua el Crepúsculo de los ídolos («Lo que debo a los antiguos», $\mathbb{} 4$ ).

8. J. Burckhardt, Die Zeit Konstantin's des Großen, Basel, 1853. Esta obra, que Nietzsche apreciaba muchísimo, le proporcionó una detallada descripción del fenómeno de los misterios en la Antigüedad tardía.

9. L. Preller, Griechische Mythologie, Leipzig: Weidmannsche Buchhandlung, 1854.

10. F. G. Welcker, Griechische Götterlehre, Göttingen: Verlag der Dieterichschen Buchhandlung, 1857-1862.

11. C.F.Hermann, Culturgeschichteder GriechenundRömer, Göttingen:K.G.Schmidt, 1857-1858. 
portante Nachhomerische Theologie de Nägelsbach ${ }^{12}$. Además de los historiadores de la Antigüedad y los filólogos, también filósofos como Hegel y Schelling y poetas como Hölderlin sufrieron la fascinación de esta espiritualidad de los misterios, imbuida de misticismo, de este «mundo de estados misteriosos» ${ }^{13}$, según la definición que dará de ellos Nietzsche en el Crepúsculo de los ídolos. El interés especulativo de Nietzsche se inserta dentro de este contexto de estudios.

Lo que designamos con el nombre de «misterios» es en realidad un conjunto variado de fenómenos religiosos esencialmente distintos por naturaleza y origen, algunos autóctonos de Grecia y otros importados de Oriente, a menudo absolutamente independientes unos de otros, heterogéneos en el plano temporal y geográfico. Hoy en día los historiadores de la religión tienden a distinguir lo más posible cada fenómeno religioso particular, y se muestran muy reticentes a la hora de aceptar sin distinción el término general de misterios. Nietzsche, en cambio, parece incluir en el término «misterios» un gran número de cultos emparentados por cierto tipo de características. Un ejemplo de este tipo de confusión es la falta de distinción por parte de Nietzsche entre los cultos mistéricos y todo tipo de cultos dionisíacos (incluidas las fiestas públicas), dos fenómenos que, hoy como antaño, los estudiosos consideran sustancialmente diferentes. Una de las grandes distinciones generales en el gran conjunto de las religiones mistéricas, que Nietzsche mismo mantiene, aunque no explícitamente, se da entre los misterios más antiguos ${ }^{14}$ (los atenienses misterios de Eleusis en honor de Deméter y Perséfone, los misterios de los Cabiros de Samotracia y los misterios de Dioniso en varias partes de Grecia), los que se desarrollaron en el siglo vi (entre los cuales Nietzsche incluye los órficos y la escuela pitagórica), y los más tardíos, que se difundieron gracias al sincretismo religioso de la koiné de la época alejandrina y greco-romana (los misterios egipcios de Isis y Osiris, los persas de Mithra, los de la Gran Madre de Frigia y Attis, y los semíticos de Sabacio).

A riesgo de caer en simplificaciones, cuando se identifican estos cultos bajo el término de misterios se quiere decir que son cultos secretos, cuyas celebraciones sólo eran accesibles a iniciados y cuyo contenido religioso estaba protegido por el mandato del silencio. Se trataba de cultos paralelos a los cultos oficiales civiles, y en muchos casos más democráticos, puesto que cualquiera que superaba la iniciación (esclavos, mujeres, extranjeros) podía acceder a ellos. Las ceremonias consistían en rituales de purificación (para los que querían iniciarse) y en ¿̇revocaciones? (dramáticas o mediante la exposición de objetos simbólicos) ¿̇de mito? del dios venerado. El contenido simbólico de estos mitos parece ser muy antiguo, ligado al simbolismo agrario, y al proceso del nacimiento y muerte en el

12. C. F. Nägelsbach, Die Nachhomerische Theologie des griechischen Volksglaubens bis auf Alexander, Nürnberg: Conrad Geiger, 1857.

13. CI, «Lo que debo a los antiguos», $\mathbb{\$} 4$, p. 134.

14. Una cuestión muy discutida en aquella época era si los cultos mistéricos se remontaban a una edad pre-homérica o más bien eran posteriores. Nietzsche, igual que Schelling (Philosophie der Mythologie, XXIII) y Rohde (Psyche) estaba convencido de la primera hipótesis, y justifica la carencia de referencias a los cultos mistéricos en los poemas homéricos como una voluntad explícita de no nombrarlos por parte del autor de los poemas. Rohde mantuvo la hipótesis de que Homero había operado un proceso de represión consciente de los cultos y doctrinas ligadas al destino del alma después de la muerte, con el fin, por así decirlo casi ilustrado, de borrar de la religión griega el temor supersticioso hacia el poder de las almas de los muertos sobre la vida terrenal. 
mundo vegetal, pero también a un simbolismo sexual, ligado a los misterios del nacimiento. A estos cultos acompañaba generalmente una doctrina escatológica, o al menos se les atribuía el poder de influir en los destinos de los iniciados después de la muerte. Generalizando de manera poco ortodoxa, el mito mistérico por antonomasia es para Nietzsche el mito órfico de Dioniso Zagreo, despedazado por los Titanes ${ }^{15}$, que el filósofo conectará con el culto eleusino de Deméter y con el mito del renacimiento del tercer Dioniso Yaco (tan importante para el Schelling de la Philosophie der Offenbarung), que heredará el mundo ${ }^{16}$.

El primer intento de Nietzsche por penetrar en el contenido de los misterios lo hallamos ya en El nacimiento de la tragedia y en los fragmentos preparatorios de esos años. Ofrecer una definición precisa de los misterios para Nietzsche en este período es difícil, puesto que presenta cierta confusión entre los distintos significados que les atribuye. Esta confusión esconde en realidad una ambigüedad de fondo. Por una parte pone en conexión los misterios con la espiritualidad mística y su expresión filosófica, la metafísica, pero por otra, igual que la tragedia, constituyen el lugar de manifestación de la esencia profunda y caótica del mundo griego. En esta dirección, Nietzsche llegará a hablar, por ejemplo, de «la doctrina mistérica de la tragedia» ${ }^{17}$. Estos planos, el místico y el dionisíaco, están estrechamente conectados con el planteamiento de fondo de El nacimiento de la tragedia y su complementariedad es posible gracias a la filosofía schopenhaueriana que está presente en el trasfondo de la obra. Estos dos momentos de la primera interpretación nietzscheana de los misterios entrarán más tarde en contradicción a lo largo del desarrollo del pensamiento del autor, a pesar de seguir siendo los dos troncos indispensables de una misma cuestión.

Para el Nietzsche de El nacimiento de la tragedia, el secreto que envolvía las prácticas de los misterios y su origen oscuro los convertía en candidatos ideales para transmitir ese saber natural y originario que había descubierto en el mundo griego. En el Mysterienruf ${ }^{18}$ de Eleusis Nietzsche veía la evocación del uno originario, el Jubelruf de Dioniso, que abría la vía que conduce a las madres del Ser ${ }^{19}$, una evocación a la que sólo el genio artístico (wagneriano) podía responder. En los misterios se manifestaba, según Nietzsche, lo dionisíaco como el fondo más

15. Los textos más importantes de la tradición órfica son los Himnos órficos y los libros de las Dionisíacas de Nonno de Panópolis. El mito órfico presenta notables variantes en su versión tebana, en particular el acontecimiento capital del despedazamiento de Dioniso por obra de los titanes. El fragmento 7[123] de los años 1870-1871 contiene un resumen del mito órfico. Según este mito, el pequeño Dioniso se identifica con Zagreo, hijo de Zeus y Perséfone. Este joven es raptado por los

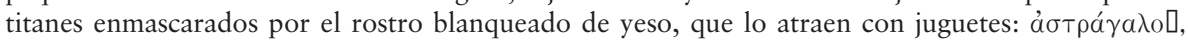

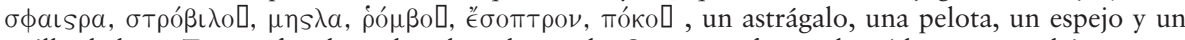
ovillo de lana. Zagreo fue despedazado y devorado. Sus restos fueron hervidos para no dejar rastro, pero Atenea salvó su corazón y le volvió a dar vida, mientras los Titanes fueron fulminados por Zeus y de sus cenizas nació el género humano.

16. Sobre la presencia de este mito en la filosofía de Nietzsche, cf. mi trabajo «'Zeus è andato in rovina a causa di suo figlio'. Prometeo, il Cristo e Dioniso in un abbozzo nietzscheano del 1874»: Intersezioni 1 (2009).

17. NT \$10, Madrid: Alianza, ${ }_{6} 1981$, p. 97.

18. La «llamada de los misterios eleusinos» NT $\mathbb{~ 1 , ~ p . ~} 41$. El grito de Eleusis proclamado por los iniciados hacia el final de la ceremonia anunciaba el nacimiento de Bromos, el hijo de Deméter, identificable con Yaco.

19. NT \ 16. Es una referencia a Goethe, Fausto, II, 6216 ss., 6427 ss. Cf. también FP I, 1870 5[2] y 18719 [106]. 
auténtico de la religiosidad griega. En esto sufría el influjo de los estudiosos de su época, que insistían en atribuir a las religiones mistéricas una espiritualidad más alta ${ }^{20}$, precisamente por ser secreta y alternativa con respecto a la religión olímpica oficial. Dioniso, en cuanto fórmula general de la espiritualidad griega más auténtica, representa para Nietzsche el dios secreto de los más antiguos misterios griegos. En las ceremonias secretas se pondrían en escena representaciones sagradas, unas pantomimas ${ }^{21}$ dirigidas a representar el mito órfico de la muerte y el renacimiento de Zagreo. El contenido de los misterios sería, por tanto, la representación de los sufrimientos de la individuación, encarnados en el mito de Dioniso Zagreo que es despedazado por los Titanes ${ }^{22}$. Este mito mismo sería también el núcleo original de la tragedia griega ${ }^{23}$, y cada héroe trágico, con sus sufrimientos, sería una máscara de Dioniso.

Junto al elemento dionisíaco que emparenta los misterios y la tragedia, Nietzsche coloca el misticismo. Tal como lo entiende, consiste en una tensión hacia lo que trasciende al hombre, que se expresa en la búsqueda de la unidad más allá del individuo y en una instancia cognitiva que intenta llegar a la esencia del mundo. Entre 1870 y 1871 se multiplican las referencias al misticismo en los escritos de Nietzsche. En primer lugar en relación con los cultos orgiásticos dionisíacos: en este sentido Nietzsche hablará de los «sentimientos místicos de unidad» que redimen (erlösen) al individuo: a través de una «autoexpresión mística ${ }^{24}$ este renuncia a su individualidad y se pierde en el dios o se reconoce en su séquito semidivino ${ }^{25}$. La tendencia mística se desarrolla de manera irrefrenable durante todo el siglo vi a.C. Según Nietzsche, a ella hay que remitir también el nacimiento de la filosofía griega: la búsqueda de la unidad arquetípica de los primeros filósofos, el paso metafísico de un Anaximandro ${ }^{26}$, «ese gélido estremecimiento de la abstracción ${ }^{27}$ de Parmémides son para Nietzsche «una

20. Durante mucho tiempo ha dominado la tesis de que los misterios griegos, y en particular el culto eleusino, representaban una religiosidad más desarrollada respecto al politeísmo griego. Incluso se había defendido la hipótesis de que se trataba de una religión monoteísta, reservada sólo a quien estuviese en condiciones de entenderla.

21. Citemos las palabras del propio Nietzsche en las lecciones Der Gottesdienst der Griechen: «Die nachahmende Handlung. Fast alle Kulte enthalten ein $\delta \rho \alpha \mu \alpha$, ein Stück dargestellten Mythus, der sich auf die Gründung des Kultus bezog» (KGW II/5, 374). Burckhardt sostiene la misma tesis en la Griechische Culturgeschichte. Estas prácticas habrían sido del mismo tipo que las representaciones medievales sagradas de los misterios pascuales y que las Moralitäten, que son herederas suyas («El drama musical griego", en NT p. 196).

22. En línea con la tradición neoplatónica (a la que recurrirá Schopenhauer), Plutarco ya había leído bajo esta clase interpretativa el mito de Dioniso: «Los sabios llaman a la trasformación en fuego Apolo, por su aislamiento, y Febo, por lo puro e inmaculado, mientras que el accidente y el cambio de su ¿̇conversación? y ordenación en aire, agua, tierra y astros y génesis de plantas y animales lo refieren en términos enigmáticos como un desgarramiento y desmembración, y lo llaman Dioniso, Zagreo, Nictelio e Isodetes, y relatan ciertas muertes y desapariciones con posteriores resurrecciones y renacimientos, en forma de enigmas e historias fabulosas apropiadas a dichas trasformaciones» (Plutarco, La E de Delphos, $\$$ 9, 389A, ed. de F. Pordomingo Pardo y J. A. Fernández Delgado, Madrid: Gredos, 1995, p. 256).

23. NT $\$ 10$.

24. NT $\$ \$ 2$ y 5 .

25. Der Gottesdienst der Griechen, KGW II/5, 374.

26. PHG $\$ 5$.

27. PHG $\$ 9$. 
creencia metafísica que tiene su origen en una intuición metafísica» ${ }^{28}$. Otras figuras encarnan para Nietzsche en este periodo la tensión mística de este siglo. Este es el caso de los poetas Jenófanes de Colofón, «el cantor de una divinización mística de la naturaleza ${ }^{29}$, y del más tardío Píndaro. Píndaro precisamente, al que Platón llamaba ó бофи́тaтo en virtud de su tono casi místico-filosófico, es para Nietzsche el cantor de los misterios ${ }^{30}:$ el contenido de sus himnos está constituido por auténticos Gedankenmysterien ${ }^{31}$. Las figuras semi-míticas de Empédocles y Pitágoras completan este panorama ${ }^{32}$, con sus doctrinas de la metempsicosis (Seelenwanderung) y de la inmortalidad del alma (Unsterblickeitsglaube) ${ }^{33}$.

Siguiendo el recorrido de la reflexión de Nietzsche sobre el mundo de los misterios en los años inmediatamente siguientes a El nacimiento de la tragedia, advertimos un importante cambio de rumbo, que parte justamente de esta asimilación de los cultos mistéricos con el misticismo. El cambio es evidente cuando se considera que Nietzsche pasa a emitir un juicio negativo con respecto a la espiritualidad mística y a ese fenómeno religioso que es expresión suya, los misterios. Atisbos de este cambio de rumbo eran observables incluso antes, en la voz que Nietzsche le daba a Heráclito, el único de los filósofos antiguos que estigmatizaba las prácticas ligadas al culto dionisíaco y en general a toda creencia supersticiosa en el más allá34. La crítica de Heráclito iba dirigida contra la lascivia que estas celebraciones permitían bajo el velo de lo sagrado ${ }^{35}$. Esta también fue la acusación que el mundo romano dirigió contra los misterios báquicos con ocasión de las condenas en torno al célebre caso de los Bacanales (Nietzsche se había ocupado de este caso en sus estudios académicos) ${ }^{36}$. Pero la crítica de Nietzsche a los cultos mistéricos atacaba más bien el lado místico. La razón de este cambio de perspectiva es el retroceso respecto a las ideas schopenhauerianas y la relativa desconfianza hacia todo tipo de pensamiento místico y ascético afín al de Schopenhauer. Pero si observamos con atención los textos de este período que atacan el fenómeno de los misterios, advertimos que los blancos de

28. PHG $₫ 3$.

29. PHG $\$ 10$.

30. Cf. Die griechischen Lyriker, KGW II/2, 154.

31. FP I, 1871 12[1].

32. «También un Pitágoras y un Empédocles se consideraban a sí mismos con una estima sobrehumana, más aún, con un temor casi religioso, pero el lazo de la compasión, unido a la gran convicción de la transmigración de las almas y de la unidad de todos los seres vivientes, les condujo de nuevo hacia los otros hombres para salvarlos» (Cinco prólogos para cinco libros no escritos, «Sobre el pathos de la verdad», trad. de L. E. de Santiago Guervós, OC I [próxima publicación]).

33. FP I, 1871 16[17].

34. «Heráclito en su odio contra el elemento dionisíaco», FP I, 1872 19[61], p. 359. En cuanto a la crítica de Heráclito al dionisismo, Nietzsche hace referencia a J. Bernays, Die Heraklitischen Briefe. Ein Beitrag zur philosophischen und religionsgeschichtlichen Litteratur, Berlin: Wilhelm Hertz, 1869.

35. Cf. Die vorplatonischen Philosophen, KGW II/4, 264-265.

36. Podemos encontrar esta resolución del senado romano en Vorlesungen über die lateinische Grammatik, KGW II/2, 302, uno de los documentos más antiguos de la lengua latina. Volvemos a encontrar ecos de esta historia en La gaya ciencia: «Los romanos temían especialmente el carácter orgiástico y dionisíaco que de vez en cuando se apoderaba de las mujeres meridionales, en esos tiempos en los que el vino era aún una novedad en Europa, y lo consideraban como un barbarismo monstruoso que socavaba de raíz el sentir romano; les parecía una traición a Roma, una incorporación de lo extranjero", $\mathrm{FW} \ 43$. 
Nietzsche ya no son los mismos de antes. Ya no se habla de Eleusis, ni del culto dionisíaco en sentido estricto, sino que Nietzsche se desplaza más adelante en el tiempo, hacia los círculos de los seguidores de Pitágoras y los órficos (que Platón ya acusara de charlatanes ${ }^{37}$ ), y se dirige hacia nuevos cultos sectarios, subterráneos y exaltados que florecieron en la gran koiné helenística de influjos orientales y nuevas exigencias espirituales.

La crítica de Nietzsche se basa en la consideración histórica de la crisis de la civilización griega clásica, de la pérdida de ese admirable equilibrio que había permitido al mundo griego de no perecer bajo los impulsos opuestos de su naturaleza. Esta crisis se vuelve patente con el final de la tragedia clásica, que había sido una válvula de escape (Ventil) de este conocimiento profundo, pesimista y místico del mundo griego ${ }^{38}$. Las etapas que Nietzsche establece en el proceso de esta crisis son muy conocidas; me limitaré a indicar aquellos aspectos del problema que afectan directamente a nuestra temática. Nietzsche contrapone directamente el desarrollo del pensamiento lógico, la aparición del ă $\nu \theta \rho \omega \pi \mathrm{Q}$ $\theta \in \omega \rho \eta т \kappa_{0}{ }^{39}$, al mundo místico de los misterios. De Sócrates, el líder de este movimiento, Nietzsche recuerda repetidamente que rechazó la iniciación a los misterios ${ }^{40}$. Con la afirmación progresiva de la visión racionalista del mundo, que rompe el equilibrio antiguo, se desencadena una reacción igualmente fuerte de carácter místico ${ }^{41}$, por parte de las instancias profundas del instinto y de la naturaleza, negadas por ese movimiento. Ya en El nacimiento de la tragedia ${ }^{42}$, Nietzsche había avanzado la hipótesis de que el elemento dionisíaco presente en la tragedia, y especialmente en el coro trágico, habría sobrevivido a esta crisis de manera subterránea en los misterios, y que a través de ellos se habría transmitido incólume a lo largo de la edad helenística y romana, para volver a emerger más tarde cuando el genio artístico pudiese volver a expresarlo. Este genio artístico debía ser obviamente Wagner, pero esta perspectiva wagneriana tendrá una vida breve en la obra de Nietzsche. El periodo que media entre 1872 y 1876 , durante el cual tiene lugar la ruptura con las ideas schopenhauerianas y sobre todo wagnerianas, nos ofrece muchas indicaciones sobre la trasformación que sufren las ideas de Nietzsche, también en lo que respecta a los misterios griegos. Entre 1875 y 1876 la terminología de los misterios empieza a aparecer en los escritos sobre Wagner, utilizada siempre metafóricamente y en sentido polémico. Se habla de los «ocultos misterios del alma» ${ }^{43}$, a los que conduciría la seductora

37. No se trata por parte de Nietzsche ėni? de Platón (República, 364e ss.) ¿̇? de una crítica a la religión órfica o a la doctrina del alma pitagórica, sino de una condena de esos aduladores que decían seguir esas enseñanzas y que se servían de ellas para embaucar a los miedosos y a los ignorantes.

38. FP I, $18693[45]$.

39. FP I, $18707[58]$

40. FP I, $18705[125], 6[14]$ y $7[96,102]$.

41. FP I, 1870 5[110], 6[12], 7[125] y 8[13].

42. «Mientras que la consideración dionisíaca del mundo nacida de ese esfuerzo sobrevive en los misterios y, a través de las más milagrosas metamorfosis y degeneraciones, no deja de atraer a sí las naturalezas más serias. ¿No volverá a ascender algún día como arte desde su profundidad mítica?», NT $₫ 17$, p. 140. En este sentido, resulta interesante la singular interpretación alegórica que Nietzsche ofrece de la narración de Dioniso huyendo de Licurgo, que se refugia en las profundidades marinas en Ilíada, VI, 132-137, cf. NT \$ 12.

43. FP I, 1871 12[33]. 
vía de la ilusión de Wagner"4, de los 'misterios' del compositor, de sus purificaciones (Reinigungen) y conmociones (Erschütterungen) ${ }^{45}$. Son el germen de esa crítica al misticismo del Parsifal de Wagner, que en los años ochenta adquirirá tonos mucho más explícitos ${ }^{46}$.

Pero el verdadero ataque a los misterios llega con el llamado periodo crítico, en Humano, demasiado humano. Como muchos otros fenómenos culturales, sociales, políticos y religiosos, los misterios son analizados para sacar a la luz sus raíces y sus elementos fundamentales. A este análisis, que revela la fragilidad, la contingencia de las realidades que se consideran estables y eternas, sigue a menudo una crítica del valor de estas realidades. En el caso de los misterios el análisis de Nietzsche se revela especialmente refinado e inteligente. Descompone el fenómeno de los misterios hasta llegar a aquello que considera que es su factor esencial, el concepto de pudor (Die Scham) ${ }^{47}$ :

Pudor. - El pudor existe donde quiera que haya un «misterio»; pero este es un concepto religioso que en los primeros tiempos de la cultura humana tenía un gran alcance. Por doquier había dominios acotados a los que el derecho divino vedaba el acceso, salvo bajo determinadas condiciones é el principio de moso? enteramente espacial, en cuanto que ciertos lugares no habían de ser hollados por el pie de los profanos y, al aproximarse a ellos, estos sentían pavor y angustia ${ }^{48}$.

Podemos observar en esta cita las influencias de los estudios etnológicos en los que Nietzsche se había interesado para sus lecciones sobre El culto griego a los dioses, donde por ejemplo hallamos un análisis del templo griego y de los niveles de sacralidad de su espacio ${ }^{49}$. Nietzsche enumera los fenómenos que tienen relación con el pudor en las sociedades de todas las épocas: los relativos a la sexualidad, que en efecto era uno de los contenidos de los misterios antiguos, los eleusinos y los dionisíacos, con sus simbolismos sexuales ${ }^{50}$. Pero también la realeza, es decir, la dignidad del poder, obtiene su sacralización a través de un proceso parecido: es revestida de misterio y por tanto de esplendor, y de estas cualidades deriva su autoridad $^{51}$ y su capacidad de producir temor. Pero también el alma misma del hombre ha sufrido una sacralización parecida:

Asimismo, para todos los no filósofos sigue siendo un misterio todo el mundo de los estados internos, la llamada «alma», tras haberse creído durante un

44. Desde este punto de vista es interesante la utilización del mito de la caverna invertido, que podemos encontrar también en $12[33]$ y en WB $\$ 6$ y que no deja dudas sobre las intenciones polémicas en las páginas de la Intempestiva.

45. WB $\mathbb{} 6$.

46. «iEsa gentuza hipócrita que con la música y el teatro desean volver a ser religiosos, que en cuanto les comienza a vibrar algo en el corazón se les mete en la cabeza desistir de toda honradez intelectual para lanzarse de cabeza en el fango místico!», FP II, 1880 6[71], p. 617.

47. Cf. también HH I $\ 472 ;$ FP II, 1875 23[79] y 1877 24[4].

48. HH I $\$ 100$, ed. de A. Brotons Muñoz, Madrid: Akal, 1996, p. 90.

49. Der Gottesdienst der Griechen, KGW II/5, 423-431.

50. HH I $\$ 112$.

51. El pudor y la sacralización que deriva de él es uno de los procesos más importantes que había constituido la sociedad que Nietzsche conocía. Denuncia su falsedad, pero reconoce también su poder y su valor. «Tan pronto como se_suscita el sentimiento de algo, p. e., de propiedad, monarquía, continúa creciendo conforme más se olvida el origen. Al final, con respecto de tales cosas se acaba hablando de 'misterios', ya que uno es consciente de la desbordante intensidad del sentimiento, pero, en sentido estricto, no puede aducirse ninguna legítima razón para ello. También aquí se hace preciso el desengaño, mas no cabe duda de que así se desperdicia una inmensa fuente de poder», FP II, 1876 23[6], pp. 327-328. 
tiempo infinito que esta era de origen divino, proveniente de un trato con la divinidad; es por tanto un ádyton y suscita pudor ${ }^{52}$.

El alma humana, su destino ultraterreno y su integridad, había sido uno de los centros de atención más fuertes de la espiritualidad de los misterios, ya desde el siglo vi a.C. Los órficos fundaban su fe en la inmortalidad del alma en el mito de Zagreo, según el cual los hombres habrían nacido a partir de los titanes incinerados por Zeus, porque habían matado y devorado a Dioniso. Por tanto, la parte más vil del hombre sería afín a los Titanes, y su parte más noble participaría del cuerpo de Dioniso. De ahí la convicción de que en el hombre hay una semilla divina que lo preserva de la muerte del alma. En general todos los cultos mistéricos creían en la distinción entre iniciados y no iniciados también más allá de la muerte. En el fragmento 7[123] de 1871, Nietzsche intenta justificar esta problemática presencia escatológica en el interior de los misterios que debían conservar el saber más profundo y pesimista del espíritu griego, interpretándola como un manera de contentar a las masas, que no estaban capacitadas para comprender la terrible sabiduría dionisíaca. Pero, de hecho, el elemento escatológico no podía ser negado, ni tampoco la connotación «moral» que parecía traer consigo, una vez que empezaba a afianzarse la idea de un juicio después de la muerte que debía distinguir a los iniciados de los profanos. Precisamente contra esta instancia escatológica de los misterios Nietzsche dirige una crítica que más adelante le resultará útil para una polémica mucho más importante contra el último gran misterio, la religión cristiana. Ya el fragmento 7[134] de 1871 alude al hecho de que el elemento místico que sobrevivió de manera latente durante toda la Antigüedad en los cultos mistéricos habría aflorado en el cristianismo, una convicción que Nietzsche resume en la sentencia válida para toda religión: «las religiones no mueren, sólo se trasfiguran» ${ }^{53}$. Esta hipótesis de la derivación del cristianismo a partir de los misterios antiguos era un leitmotiv de la cultura alemana de aquella época, no sólo en el ámbito de los estudios históricos, sino también de los teológicos y filosóficos. Nietzsche recopila estas teorías y sostiene que la religión de los misterios habría preparado el terreno al cristianismo y a la conquista de los últimos bastiones del mundo antiguo.

La corriente del misticismo subterráneo de los misterios encontró un terreno fértil en ese mundo helenístico de confines dilatados y carente de centros, que había reemplazado a la unidad política de la polis. Cuando la polis griega entró en crisis, y el nuevo mundo helenístico hizo emerger las exigencias del individuo, estos cultos se multiplicaron y se difundieron enormemente. Las exigencias del individuo se volvieron prominentes, y a ellas pertenece el deseo de la salvación individual, de la inmortalidad personal. La doctrina de la salvación personal sería, en efecto, para Nietzsche, uno de los factores más evidentes del carácter subversivo que debieron de tener los misterios en Grecia, de su oposición al poder estatal de la polis, que celebraba los cultos oficiales a la luz del día. La misma vocación popular y democrática de los misterios, abiertos a capas sociales carentes de reconocimiento en la polis, contrastaba netamente con los ideales políticos griegos. Con el advenimiento de los reinos helenísticos, el ciudadano es reemplazado por el individuo privado, la comunidad por el individuo. Miles de cultos mistéricos dieron voz a las reivindicaciones y esperanzas de personas

52. HH I $\$ 100$, p. 90.

53. Encyclopädie der klassichen Philologie, KGW II/3, 348. 
de todo el cosmos alejandrino. Sincretismo y cosmopolitismo serían las nuevas características dominantes de cultos como el pseudo-egipcio de Isis, el persa de Mithra y el culto renovado y trasformado a la gran madre frigia y a Attis.

¿Cómo consiguió el cristianismo, un pequeño movimiento popular surgido en el seno del judaísmo, en la más lejana provincia romana, conquistar el mundo? A la koiné alejandrina sucedió la gran paz del imperio romano, la más sólida arquitectura política de todos los tiempos. El cristianismo consiguió triunfar conquistando el imperio romano y utilizándolo como estructura unificadora y centralizadora. Este movimiento se convirtió en la expresión de todos esos diferentes fermentos anárquicos y subversivos que se anidaban subterránea y desorganizadamente en el vasto imperio romano. La teocracia ${ }^{54}$ establecida por Alejandro Magno primero y luego por los romanos había demostrado una gran eficacia política, pero ya no llegaba a las masas, entre las cuales se difundía una incredulidad cada vez mayor. El cristianismo recogió la herencia de todos los descontentos, de todos los temerosos que llenaban los cultos secretos buscando en ellos respuestas espirituales a sus propios temores. Pero para convertirse en portavoz de estas necesidades, fue preciso que el cristianismo se desarrollase y que desarrollase un lenguaje que lo hiciese capaz de esa representación universal. Se hizo sincrético para acoger en sí mismo todos los elementos de un mundo dilatado y diversificado. El artífice de esta maniobra, mediante la cual el cristianismo englobó en su interior toda la tradición espiritual del politeísmo antiguo, fue, según Nietzsche, Pablo de Tarso ${ }^{55}$.

Entonces apareció Pablo... Pablo, el odio, hecho carne, hecho genio, del chandala contra Roma, contra «el mundo», contra el judío, el judío eterno par excellence... Lo que él adivinó fue el modo como, con ayuda del pequeño movimiento sectario de los cristianos, al margen del judaísmo, se podía provocar un «incendio mundial», el modo como, con el símbolo «Dios en la cruz», se podía aglutinar en un poder enorme todo lo que se encontraba abajo, todo lo que era secretamente rebelde, la herencia entera de las intrigas anarquistas en el imperio. «La salvación viene de los judíos» ${ }^{56}$.

El «instante de Damasco» de Pablo, su iluminación, consistió en su capacidad de descubrir los temores de su época y darles una voz universal ${ }^{57}$. Pablo de Tarso

54. En la Encyclopädie der klassichen Philologie und Einleitung in das Studium derselben (KGW II/3, 410-419) Nietzsche introduce el concepto de teocracia para explicar el sincretismo entre distintas religiones en la época helenística y en la romana, y para indicar la institucionalización de los cultos de estado en el gran imperio, dirigidos a venerar divinidades extranjeras junto a las de los conquistadores, y su pretensión de universalidad.

55. La tesis de que Pablo de Tarso fue el verdadero fundador del ¿́cristianismo moderno? es una teoría tradicional de los estudios teológicos y que en la época de Nietzsche estaba siendo muy discutida. Por citar sólo las contribuciones contemporáneas a Nietzsche, cf. D. F. Strauss, Das Leben Jesu, Tübingen, 1835-1836; Íd., Der alte und der neue Glaube, Leipzig: Hirzel, 1872; A. Hausrath, Der Apostel Paulus, Tübingen, 1872; Íd., Neutestamentliche Zeitgeschichte, Tübingen, 1868-1874; H. Lüdemann, Die Anthropologie des Paulus, 1872; F. Overbeck, Ueber die Christlichkeit unserer heutigen Theologie, Leipzig: Fritzsch, 1873. Se compartía la idea de que Pablo había dado al cristianismo primitivo un alcance universal, con capacidad de permanecer, y por tanto lo volvió más dogmático: Pablo de Tarso habría trasformado el cristianismo espiritual de los orígenes en una iglesia y una doctrina teológica.

56. AC $\$ 58$, Madrid: Alianza, ${ }_{11} 1985$, p. 103.

57. «Pablo, con instinto para las necesidades de los no-judíos», FP IV, 1887 11[281], p. 436. 
tomó los símbolos del primitivo movimiento cristiano y los tradujo a las necesidades concretas de las masas ${ }^{58}$, explotando de esta manera el patrimonio de la espiritualidad pagana. A estos contenidos universales debía también corresponder una lengua universal, el griego; así los tradujo Pablo, literalmente, tomando prestada la palabra griega «misterios» $»^{59}$. La fuerza del cristianismo creado por Pablo de Tarso es su sincretismo, casi mimético, que lo convierte en intérprete universal de las necesidades de su época y de sus necesidades de cambio.

La iglesia cristiana es una enciclopedia de cultos prehistóricos y de intuiciones del origen más diverso, de ahí su capacidad misionera: antaño podía llegar y hoy en día llega a cualquier sitio, siempre se encontraba y se encuentra con algo semejante con lo que puede concordar, para sustituir poco a poco su significado. La base para la difusión de esta religión mundial no es el elemento cristiano que hay en ella, sino el elemento universal y pagano de sus usos ${ }^{60}$.

El cristianismo retoma una lucha contra el paganismo que ya se había iniciado dentro del paganismo mismo, volviendo a confirmar la oposición contra la unidad de la religión olímpica, espejo de la unidad estatal de la polis.

En resumen: el cristianismo se adapta al antipaganismo ya existente, implantado por todas partes, a los cultos que Epicuro había combatido... con mayor exactitud, a las religiones de la masa inferior de las mujeres, de los esclavos, de los estamentos NO-NOBLES. ${ }^{61}$

En este importante fragmento 11[295], Nietzsche enumera los elementos que Pablo traslada de los misterios paganos al cristianismo: analicemos algunos de ellos.

En primer lugar: «1) La esperanza en el más allá». El Jesús de Pablo debía resultar muy familiar a los adoradores de Mithra, de Dioniso, de Adonis y de Attis ${ }^{62}$, todas ellas divinidades que, con su muerte y resurrección, garantizaban al hombre un destino después de la muerte. La esperanza en el más allá era compensada por el miedo, al introducir la perspectiva del premio/castigo después de la muerte, que ya había aparecido en los cultos mistéricos con la división de iniciados/no-iniciados. Pero no todo el mundo pagano estaba dominado por estos temores y, lo que es más importante, tampoco el cristiano en sus orígenes:

$E l$ «Más allá de la muerte». [...] Los primeros cristianos estaban muy lejos del pensamiento de los tormentos eternos; ellos pensaban estar liberados «de la muerte» y esperaban día tras día una transmutación y no una muerte ${ }^{63}$.

58. Nietzsche habla precisamente de la trasformación de lo Symbolische del cristianismo en Cruditäten, cf. FP IV 1887, 11[295].

59. Por citar sólo algunos de los numerosos pasajes, Pablo habla de misterios escondidos largo tiempo (1 Cor 2,6; Col 1,26; Ef. 5,32), de misterios de Dios (1 Cor 4,1) o de Cristo (Ef 3,4; Col 4,4) que él da a conocer tanto a paganos como a gentiles, para que participen de ellos.

60. $\mathrm{M} \ 70$.

61. FP IV, 1887 11[295], p. 442.

62. Este parecido entre las figuras de Jesús y las divinidades de los cultos histéricos, además de las semejanzas litúrgicas, ya habían sido resaltadas por los primeros apologistas cristianos, que las consideraban engaños del diablo para confundir a las almas.

63. M $\$ 72$. Según Nietzsche y íotros? muchos teólogos de su tiempo, los primeros cristianos esperaban la llegada del reino de Dios sobre la tierra, lo esperaban como algo próximo y tomaban al pie de la letra la promesa de la liberación de la muerte. Pero cuando se volvió patente que este acontecimiento no se iba a producir en el lapso de una generación, se volvió necesario replantear la doctrina de tal manera que durase a lo largo de los siglos: así nacieron la iglesia y la doctrina teológica. 
El mismo caso de la religión judía, de cuyo seno surgió el cristianismo, es ejemplar. Los judíos se preocupaban poco del destino ultraterreno, no conocían la idea de premio o de castigo en el más allá. De los misterios Pablo supo aprovechar tanto la promesa de la inmortalidad del alma como la amenaza de una condenación eterna. Esta última perspectiva se reveló, según Nietzsche, como particularmente eficaz para aquellos pueblos que no se preocupaban en absoluto del beneficio más allá de la muerte, pero en los que sí podía provocar temor la idea de que la vida ultraterrena fuese un infierno: "con el 'más allá' se mataba la vida» ${ }^{64}$.

El segundo punto, «2) la cruenta fantasmagoría del animal ¿́sacrificial 'el misterio'? tiene un interés especial. El sacrificio cruento estaba en la base de todos los cultos de la Antigüedad, y para los cultos mistéricos representaba incluso el acontecimiento fundador: el mito del dios que moría como víctima sacrificial era repetido en los rituales, y constituía el contenido de la doctrina sagrada. También el cristianismo celebraba este sacrificio en la Eucaristía, pero de manera más sustancial en su mismo símbolo, en el escándalo de la cruz:

¿Algo que iguale en fuerza atractiva, embriagadora, aturdidora, corruptora, a aquel símbolo de la «santa cruz», a aquella horrorosa paradoja de un «Dios en la cruz», a aquel misterio de una inimaginable, última, extrema crueldad y autocrucifixión de Dios para salvación del hombre?... ${ }^{65}$.

El nuevo culto mistérico del cristianismo sustituyó el Jubelruf de los misterios antiguos por el grito «iMás dolor! imás dolor!» ${ }^{66}$, con el que el ascetismo pagano triunfaba sobre la vida despreciando el cuerpo. Se recupera aquí, por tanto, completamente trasformado, ese misticismo nacido en Grecia como una tensión extrema hacia la fuente de la existencia, dándole la forma de la práctica sacerdotal de la negación de la existencia misma.

Nietzsche profundiza ulteriormente la noción de sacrificio que emparenta los misterios y el cristianismo y desarrolla sobre ella una interesante reflexión filosófica:

Existe una larga escalera de la crueldad religiosa, que consta de numerosos peldaños; pero tres de estos son los más importantes. En otro tiempo la gente sacrificaba a su dios seres humanos [...] Después, en la época moral de la humanidad, la gente sacrificaba a su dios los instintos más fuertes que poseía, su «naturaleza» ${ }^{67}$.

El sacrificio de los instintos es el sacrificio propuesto por el cristianismo, mediante la propuesta ascética y la aniquilación del hombre bajo el peso de la culpa por la muerte del dios. Pero cuando habla del sacrificio humano, Nietzsche siempre tiene en mente dos episodios muy precisos de la Antigüedad. El primero es el conocido caso, contado por Plutarco en la Vida de Temístocles, de los tres jóve-

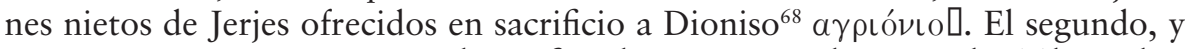
que aquí más nos interesa, es el sacrificio humano que el emperador Tiberio habría llevado a cabo en Capri, en una gruta sagrada, al dios solar Mithra durante

64. AC $\$ 58$, p. 104.

65. GM I $\$ 8$, Madrid: Alianza, 7 1983, p. 41.

66. GM III $\$ 20$, p. 164.

67. MBM $\$ 55$, Madrid: Alianza, ${ }_{8} 1983$, p. 80.

68. Plutarco, Temístocles, 13. El episodio es recordado a menudo por Nietzsche, cf. FP I, 1870 $7[61,81,123]$. 
un ritual mistérico. Toda una serie de fragmentos del período 1878-1879 habla más o menos explícitamente de este suceso y de la gruta donde la tradición dice que ocurrió el sacrificio ${ }^{69}$, definido por Nietzsche como «el más horrible de todos los anacronismos romanos» ${ }^{70}$. El acto de Tiberio es una aberración, no tanto por ser el asesinato de un hombre, sino porque este acto que un emperador lleva a cabo con su propia mano niega por sí mismo lo que Roma representaba como instancia racional, civil y terrenal ${ }^{71}$. El sacrificio del esclavo Hípato sancionó el final de Roma y su progresiva rendición a las corrientes místicas que la minaban por dentro, y que llegarán a la victoria con el cristianismo.

Esa organización era lo bastante firme como para soportar malos emperadores: en tales cosas el azar de las personas no tiene nada que hacer, - primer principio de toda gran arquitectura. Pero no era suficientemente firme contra la especie más corrompida de corrupción, contra el cristiano... [...] Los rodeos de los santurrones, la clandestinidad de los conventículos, unos conceptos lóbregos, tales como infierno, como sacrificio del inocente, como unio mystica en el beber sangre ${ }^{72}$.

El análisis de las tipologías del sacrificio concluye en Más allá del bien y del mal con un tercer tipo, el que según Nietzsche tiene frente a sí la humanidad actual: el sacrificio de Dios. Ya no se trata del sacrificio del dios en el mito de los misterios, ni del sacrificio de Jesús que vuelca sobre los hombres la culpa de su muerte inocente. Ahora el dios, como última riqueza y último bien, es sacrificado a la nada. El oficiante de este extremo sacrificio es el último hombre. Esta es la suprema crueldad del sacrificio, la crueldad máxima del hombre hacia sí mismo:

Sacrificar a Dios por la nada - este misterio paradójico de la crueldad suprema ha quedado reservado a la generación que precisamente ahora surge en el horizonte: todos nosotros conocemos ya algo de esto - ${ }^{73}$.

Otro punto importante del fragmento $11[295]$ es el cuarto ${ }^{74}$, que cita la Reinigung, las prácticas catárticas, los ritos de purificación comunes a todos los cultos antiguos. El concepto de purificación en la Antigüedad no tenía nada que ver con nuestro actual concepto de expiación. La purificación servía para liberar al hombre de un estado de contagio (miasma) que derivaba de haber tenido contacto con algo impuro, algo externo que modificaba la integridad de la persona. Los agentes portadores del miasma eran esos mismos fenómenos hacia los que, como hemos visto, se experimenta el sentimiento del pudor: por ejemplo, los actos sexuales o la violación de un lugar sagrado. También el homicidio volvía impuros, pero sin añadirle ninguna connotación moral. La contaminación para quien había cometido un delito derivaba del contacto con la sangre del asesina-

69. FP II, 1878 28[17, 22, 24, 25, 34, 39]. La fuente de estos fragmentos es F. Gregorovius, Figuren. Geschichte, Leben und Scenerie aus Italien, Leipzig, 1856, pp. 360 ss. La gruta de Capri donde se habrían producido los sacrificios había sido visitada por Nietzsche durante su estancia en Sorrento. Gregorovius propone una serie de hipótesis etimológicas del extraño nombre de la gruta (modificado popularmente por la "Gruta del matrimonio») que lo remiten al culto mistérico del dios Mithra y al culto de la gran Madre (de ahí «mitromania» o «matromania»).

70. MBM $\$ 55$, p. 55.

71. Son muy bellas las palabras que Nietzsche pone en boca de Tiberio en el momento de su «doble muerte», cf. FW $\$ 36$.

72. $\operatorname{AC} \$ 58$, p. 103 .

73. JGB $\$ 55$, p. 81 .

74. Los otros puntos son: «3) el acto redentor, la leyenda sagrada [... 5) una jerarquía, una forma de organización de la comunidad». 
do; incluso la cercanía de un muerto por causas naturales podía volver impuro. Las prácticas de purificación servían por tanto para «limpiar» lo impuro de algo externo que lo había manchado, lo que no tenía nada que ver con su responsabilidad. En este aspecto de las antiguas prácticas catárticas insiste Burckhardt en su Culturgeschichte, y también Nietzsche en el capítulo ${ }^{75}$ que dedica a Die Reinigung kavqarsi lustratio (suffimentum, expiatio, purgatio) en las lecciones Der Gottesdienst der Griechen. No es casualidad que los medios mediante los cuales se obtenía la purificación durante estas prácticas sean los instrumentos más elementales de limpieza: el agua, el fuego y la ceniza. Lo que diferencia a la práctica antigua de la purificación del concepto moderno y cristiano de expiación, es la noción de culpa. La trasformación de la purificación antigua en expiación habría ocurrido ya, según Nietzsche, dentro de la cultura griega, con la introducción de un primitivo concepto de culpa indispensable para justificar el sistema de premios/castigos de las sectas mistéricas ${ }^{76}$. Burckhardt ya había observado en la Culturgeschichte que si la exterioridad era la característica de las prácticas normales de purificación necesarias para la iniciación en los misterios, los órficos demostraron otorgarle ya un significado más profundo a estas purificaciones, y atribuirles el poder de operar una metamorfosis interior.

Cerremos este breve estudio con el concepto de expiación, y concluyamos de manera quizás inesperada, volviendo al principio, redescubriendo al final del recorrido filosófico y crítico de Nietzsche los misterios bajo la forma de su antiguo esplendor. Si bajo muchos aspectos el cristianismo ha seguido fielmente la lección de los misterios, y más aún, fue preparado por ellos, en un caso al menos Nietzsche no admite esta filiación. La expiación cristiana busca la redención a través del dolor que conduce a la ascesis. También los misterios tenían su doctrina del dolor, pero iba dirigida a un fin contrario:

En la doctrina de los misterios el dolor queda santificado: los «dolores de la parturienta» santifican el dolor en cuanto tal - todo devenir y crecer, todo lo que es una garantía del futuro implica dolor... Para que exista el placer del crear, para que la voluntad de vida se afirme eternamente a sí misma, tiene que existir también eternamente el «tormento de la parturienta»... ${ }^{77}$.

Los griegos se garantizaban la vida eterna con sus cultos mistéricos, pero no la pálida sombra de vida del más allá cristiano, sino la verdadera vida, el eterno retorno de la vida, «el futuro prometido y consagrado en el pasado» ${ }^{78}$, la plenitud de vida que es también dolor y muerte y de nuevo vida. Este era el saber de los griegos y el contenido de sus misterios para el último Nietzsche: «Yo he descubierto lo helénico: icreían en el eterno retorno! iEs la fe de los misterios! ${ }^{79}$.

[Traducción de Marco Parmeggiani]

75. Der Gottesdienst der Griechen, KGW II/5, 504-514.

76. Encyclopädie der klassischen Philologie, KGW II/3 413.

77. CI, «Lo que debo a los antiguos», $\mathbb{\$} 4$, p. 135.

78. CI «Lo que debo a los antiguos», $\mathbb{S} 4$, p. 134.

79. FP III, 1883 8[15], p. 237. 